\title{
Pulmonary Mycobacterial Granuloma
}

\section{Increased IL-10 Production Contributes to Establishing a Symbiotic Host-Microbe Microenvironment}

Christopher R. Shaler, Kapilan Kugathasan, Sarah McCormick, Daniela Damjanovic, Carly Horvath, Cherrie-Lee Small, Mangalakumari Jeyanathan, Xiao Chen, Ping-Chang Yang, and Zhou Xing

From the Department of Pathology and Molecular Medicine, Centre for Gene Therapeutics, and M.G. DeGroote Institute for Infectious Disease Research, McMaster University, Hamilton, Ontario, Canada

The granuloma, a hallmark of host defense against pulmonary mycobacterial infection, has long been believed to be an active type 1 immune environment. However, the mechanisms regarding why granuloma fails to eliminate mycobacteria even in immune-competent hosts, have remained largely unclear. By using a model of pulmonary Mycobacterium bovis Bacillus Calmette-Guerin (BCG) infection, we have addressed this issue by comparing the immune responses within the airway luminal and granuloma compartments. We found that despite having a similar immune cellular profile to that in the airway lumen, the granuloma displayed severely suppressed type 1 immune cytokine but enhanced chemokine responses. Both antigen-presenting cells (APCs) and T cells in granuloma produced fewer type 1 immune molecules including tumor necrosis factor- $\alpha$ (TNF$\alpha)$, interferon- $\gamma($ IFN- $\gamma)$, and nitric oxide. As a result, the granuloma APCs developed a reduced capacity to phagocytose mycobacteria and to induce T-cell proliferation. To examine the molecular mechanisms, we compared the levels of immune suppressive cytokine IL-10 in the airway lumen and granuloma and found that both granuloma APCs and $T$ cells produced much more IL-10. Thus, IL10 deficiency restored type 1 immune activation within the granuloma while having a minimal effect within the airway lumen. Hence, our study provides the first experimental evidence that, contrary to the conventional belief, the BCG-induced lung granuloma represents a symbiotic host-microbe microenvironment characterized by suppressed type $1 \mathrm{im}$ mune activation. (Am J Pathol 2011, 178:1622-1634; DOI: 10.1016/j.ajpath.2010.12.022)

Secondary only to HIV, pulmonary tuberculosis remains a leading cause of death by a single infectious pathogen. ${ }^{1-3}$ Pulmonary infections caused by other mycobacterial species also often pose a serious problem to immune-compromised hosts. ${ }^{4-6}$ After mycobacterial infection in the lung, the host attempts to control the infection by locally segregating the bacteria in a granuloma formed under type 1 immune conditions. ${ }^{7-10}$ Granuloma formation is thus the pathological hallmark of pulmonary mycobacterial infection readily detectible on a radiographical image. The granuloma is an organized collection of inflammatory and immune cells primarily composed of infected macrophages, recruited dendritic cells, and activated lymphocytes. The evolution of the granuloma is divided into two stages. First, the initial formation of the "innate" granuloma comprises early recruited innate immune cells including macrophages, dendritic cells, and neutrophils, which function to contain early mycobacterial infection and to recruit adaptive immune components. Second, the formation of the "immune" granuloma is hallmarked by the arrival of antigenspecific $T$ lymphocytes and the activation of infected macrophages to further control internalized mycobacteria. $^{9,10}$ The "immune" granuloma formation is not fully developed until 21 to 25 days, the time when maximal antigen-specific $T$ cells reach the lung. ${ }^{3}$ On arrival in the lung, some antigen-specific T cells remain in the interstitium, presumably assisting in the formation of the "im-

\footnotetext{
Supported by funds from the Canadian Institutes for Health Research. Accepted for publication December 9, 2010.

Address reprint requests to Zhou Xing, M.D., Ph.D., Room 4012-MDCL, Department of Pathology \& Molecular Medicine, McMaster University, 1200 Main St W, Hamilton, ON L8N 3Z5, Canada. E-mail: xingz@ mcmaster.ca.
} 
mune" granuloma, whereas others enter the airway lumen. It has long been believed that the granuloma represents purely a host response mechanism, creating an immune-active microenvironment to concentrate antimycobacterial immune responses, contain infection, and limit systemic dissemination. ${ }^{2,3}$ This belief is based mainly on the findings from us and others that the inability of the host to form or maintain granuloma structures as a result of either lacking or having dysregulated type 1 immune responses will inevitably lead to uncontrolled mycobacterial infection in the lung and severe disseminated disease. 2,3,10-15

However, the notion that the granuloma is an immune-active microenvironment formed solely as a mechanism for the host to control infection and limit systemic dissemination has recently been challenged. There is the evidence that by expressing a set of "persistence" genes, the mycobacterium, together with the host, contributes to granuloma formation as a mechanism to facilitate bacterial dissemination and persistence. ${ }^{16,17}$ This suggests that the granuloma microenvironment is subject to immune subversive influences from mycobacteria throughout the course of infection. Furthermore, recent studies demonstrate that mycobacteria would rather make the granuloma their home than the extragranuloma environment, ${ }^{18,19}$ suggesting that the granuloma is permissive to mycobacterial survival and persistence while also being immune-protective. Indeed, even infected immune-competent human beings or animals have hardly ever been observed to eliminate the mycobacteria, resulting in a high incidence of latent infection and the reactivation of disease when the immune system is weakened. ${ }^{20,21}$ Together, the emerging evidence supports the contemporary view that the granuloma represents a symbiotic tissue microenvironment for the mutual benefit of both the host and the mycobacterium. However, whether the mycobacterial granuloma is indeed an immunologically suppressed microenvironment remains largely to be established, and the underlying mechanisms are still unclear. Investigation of such questions entails the understanding and comparison of the phenotype and functional characteristics of the immune cells both inside and outside of the granuloma.

In the present study, we have addressed this issue by using a murine model of pulmonary mycobacterial infection elicited by Mycobacterium bovis Bacillus Calmette-Guerin (BCG). We found that, compared with the antigen-presenting cells (APCs) and T cells residing within the airway luminal (bronchoalveolar) space outside of the granuloma, the cells from the granuloma were functionally immune suppressed. Such an immune-suppressed phenotype of the granuloma cells was characterized by heightened production of the immune-regulatory cytokine IL-10. Thus, the absence of IL-10 restored the type 1 immune responses and antimycobacterial activities in the granuloma. Together, our study findings strongly suggest that, during pulmonary mycobacterial infection, the airway lumen and the granuloma represent two immunologically dif- ferent lung microenvironments, with the latter being immune suppressed.

\section{Materials and Methods}

\section{Mice}

Female $\mathrm{C} 57 \mathrm{BI} / 6$ mice 6 to 10 weeks old were purchased from Harlan Laboratories, (Indianapolis, IN). IL-10 knockout mice of C57BI/6 background (B6.129P2\|10tm1Cgn/J) were purchased from Jackson Laboratories (Bar Harbor, ME). Mice were housed in a specific pathogen-free level B facility. All experiments were conducted in accordance with the McMaster University Animal Research Ethics Board.

\section{Mycobacterial Preparation and Model of Pulmonary Mycobacterial Granuloma Formation}

M. bovis BCG (Connaught strain) was prepared as previously described. ${ }^{12,22}$ Briefly, BCG was grown in Middlebrook 7H9 broth (Difco, Lawrence, KS) supplemented with Middlebrook OADC enrichment (Invitrogen), 20\% glycerol, and $0.05 \%$ Tween 80 for 10 to 15 days, and samples were then divided into aliquots and stored at $-70^{\circ} \mathrm{C}$. Before each use, a BCG aliquot was washed twice with phosphate-buffered saline (PBS) containing $0.05 \%$ Tween 80 and resuspended in PBS. It was then passed through a 27-gauge needle 10 times to disperse clumps and diluted with PBS to the desired concentration. Mice were infected intratracheally with a dose of $10^{6}$ colony forming units (CFU) per mouse for elicitation of vigorous granuloma formation.

\section{Isolation of Granuloma and Airway Luminal Cells from Mycobacterium-Infected Lungs}

We have previously observed that pulmonary "immune" granulomatous responses peak at approximately day 25 postinfection. ${ }^{11,12}$ Thus, mice were sacrificed 25 days after mycobacterial infection to allow for sufficient yields of total and fractionated airway lumen and granuloma immune cells. Mice were first bled via the abdominal vessels and their lungs were exhaustively lavaged with PBS to remove bronchoalveolar lavage cells following our previously described protocol. ${ }^{23}$ Lung granulomas were then isolated by using a well-established protocol. ${ }^{24-26}$ Briefly, the lavaged lungs were homogenized in a tissue blender (Waring Commercial, Torrington, CT) using the low speed setting for 10 to 15 seconds, which leaves the granulomas intact. Lung granuloma-containing homogenates were then filtered through a 40- $\mu \mathrm{m}$ cell strainer. Granulomas collected on top of the filter were then digested with collagenase type 1 (Sigma-Aldrich, Oakville, ON, Canada) (2000 units $/ \mathrm{mL}$ in a volume of $5 \mathrm{~mL} / \mathrm{lung}$ ) for 20 minutes under agitation at $37^{\circ} \mathrm{C}$ and washed three times with 5\% FBS in PBS. Red blood cells in granuloma cell preparations were lysed using ACK lysis buffer and the cells were then washed with 5\% FBS in PBS and filtered through a $40-\mu \mathrm{m}$ cell strainer. Cells were spun 
down and resuspended in CRPMI media (RPMI 1640 supplemented with $10 \%$ fetal bovine serum, $1 \%$ L-glutamine, and $1 \%$ penicillin/streptomycin) and counted. Cell viability was determined by Trypan Blue exclusion.

\section{Purification of $C D 11 c+$ and $C D 11 b+A P C$ Populations from Total Airway Luminal and Granuloma Cells}

Single cell suspensions of total airway lumen and granuloma cells isolated above from multiple mice were pooled and then first incubated with CD11c microbeads (Miltenyi Biotec, Auburn, CA) for purification of $\mathrm{CD} 11 \mathrm{c}+\mathrm{CD} 11 \mathrm{~b}+/-\mathrm{APC}$ as we recently described. ${ }^{27}$ CD11c-labeled cells were then passed through a mass spectrometry (MS) column on the OctoMACS separator (Miltenyi Biotec, Auburn, CA). Samples were run through magnetically activated cell sorting (MACS) separation columns twice to achieve high purity. Collected CD11cnegative fractions were then further labeled with CD11b microbeads (Miltenyi Biotec, Auburn, CA) according to the manufacturer's instructions and passed through the MACS column twice for isolation and enhanced purity of CD11c-CD11b+ APCs. Cells were counted and their viability was verified by Trypan blue exclusion. Purity of recovered $\mathrm{CD} 11 \mathrm{c}+\mathrm{CD} 11 \mathrm{~b}+/-$ and CD11c-CD11b+ APC populations was determined by fluorescence-activated cell sorting (FACS) and was consistently $>90 \%$.

\section{Cell Surface Immunostaining and Intracellular Cytokine Staining}

All monoclonal antibodies (mAbs) used were purchased from BD Pharmingen. Immunostaining and FACS were carried out as previously described. ${ }^{12,22,28}$ Briefly, cells were blocked for nonspecific binding of their Fc receptors with anti-CD16/CD32 Abs for 15 minutes and then stained for 30 minutes on ice with the appropriate combinations of fluorochrome-conjugated mAbs. Fluorochrome-conjugated mAbs to CD11b, CD11c, Gr.1, CD19, NK1.1, CD3, CD4, and CD8 were used. Appropriate isotype controls were used for each antibody. For intracellular cytokine staining, single cell suspensions from airway lumen and granuloma were cultured and stained as previously described. ${ }^{29}$ Briefly, cells were cultured for 24 hours with or without mycobacterial antigens [M.tb-Culture Filtrate (CF) and crude BCG], Golgi Plug (5 $\mu \mathrm{g} / \mathrm{mL}$ brefeldin A; BD Bioscience, Burlington, ON, Canada) was added 18 hours after stimulation. After culture, cells were washed and blocked with CD16/CD32 for 15 minutes on ice and stained with cell surface Abs. In some experiments, cells were then washed, permeabilized and stained with interferon- $\gamma$ (IFN- $\gamma$ ), and IL-10 Abs according to the manufacturer's instructions included in the intracellular cytokine staining kit (BD Pharmingen). Stained cells were run on the LSRII (BD Biosciences, Mississauga, ON, Canada) flow cytometer using FACSDiva software and data were analyzed with Flowjo software (Tree Star, Ashland, OR). Depending on the number of cells available, 100,000 to 250,000 events per sample were analyzed.

\section{Cell Culture and Cytokine Measurement}

Total airway lumen and granuloma cells $\left(0.25 \times 10^{6} /\right.$ well) or purified CD11c+ and CD11b+ APC fractions from the airway lumen and granuloma $\left(0.1 \times 10^{6} /\right.$ well $)$ were seeded into a 96-well, flat-bottom plate and cultured at $37^{\circ} \mathrm{C}$ and $5 \% \mathrm{CO}_{2}$ with or without mycobacterial antigen stimulation. The antigens used for stimulation were $M$. tuberculosis culture filtrate proteins (M.tb-CF) (2 $\mu \mathrm{g} /$ well) or live M. bovis BCG ( 5 CFU/cell or $2 \mathrm{CFU} /$ cell for total and purified cell cultures, respectively). Cells were cultured in a total volume of $250 \mu \mathrm{L}$ of cRPMI. Culture supernatants were collected at 48 hours and stored at $-20^{\circ} \mathrm{C}$ until cytokine/chemokine measurement. TNF- $\alpha$, IFN- $\gamma$, and IL-10 concentrations were measured by using duoset ELISA kits (R\&D Systems) and IL-17, keratinocyte chemoattractant, macrophage inflammatory protein- $1 \beta$, and monocyte chemoattractive protein-1 were measured by Luminex multianalyte technology (Luminex Corporation, Austin, TX).

\section{Nitric Oxide Production Measurement}

The release of nitric oxide (NO) by airway lumen and granuloma derived cells was determined by measuring the end product of NO, nitrite, as previously described. ${ }^{30}$ Briefly, diluted supernatants were added at a 1:1 ratio with Griess reagent buffer (Sigma-Aldrich, St Louis, MO). The absorbance was measured at $540 \mathrm{~nm}$ by a spectrophotometer. The final concentration of nitrite was calculated by referring to a standard curve prepared from 0 to $100 \mu \mathrm{mol} / \mathrm{L}$ of sodium nitrite concentrations.

\section{Mycobacterium Phagocytosis Assay by Flow Cytometry and Confocal Microscopy}

To fluorescently detect bacterial uptake by APCs, $M$. bovis BCG was labeled with 5,6-carboxyfluorescein diacetate succinimidyl ester (CFSE) for 30 minutes at room temperature to ensure a high level of binding. After CFSE labeling, BCG was opsonized with naive C57BL/6 serum at $37^{\circ} \mathrm{C}$ for 30 minutes. Subsequently, $0.25 \times 10^{6}$ purified $\mathrm{CD} 11 \mathrm{c}+$ cells were combined with fluorescence-labeled BCG-CFSE (5 CFU/cell) in a 96-well plate and co-cultured at $37^{\circ} \mathrm{C}$ overnight. After overnight co-culture, cells were blocked for nonspecific binding of their Fc receptors with anti-CD16/CD32 for 15 minutes on ice and then stained with $\mathrm{mAb}$ against $\mathrm{CD} 11 \mathrm{c}+$ and $\mathrm{CD} 11 \mathrm{~b}+(\mathrm{BD}$ Biosciences) for 30 minutes. To evaluate the uptake of mycobacteria by APC populations, stained cells were run on the LSRII (BD Biosciences, Mississauga, ON, Canada) flow cytometer using FACSDiva software, and data were analyzed with Flowjo software (Tree Star, Ashland, $\mathrm{OR}$ ) to determine the frequency of bacterial uptake by the percentage of cells that stained CD11b+CFSE+ and $\mathrm{CD} 11 \mathrm{c}+\mathrm{CFSE}+$. Depending on the number of cells available, 100,000 to 250,000 events per sample were ana- 
lyzed. In an independent setup, CD11c+ cells were purified by MACS double column purification from infected airway luminal and granuloma cells. Purified CD11c+ cells $\left(0.25 \times 10^{6}\right)$ were cultured overnight with opsonized, fluorescence-labeled BCG prepared as described above. After overnight culture, cells were fixed for 30 minutes using 2\% paraformaldhyde, washed three times with PBS, followed by 30-minute staining with $\mathrm{PI}$, a DNA intercalating agent with fluorescent properties, allowing the visualization of the nucleus. After PI staining, cells were imaged for $\mathrm{PI}$ and CFSE localization using a Zeiss LSM10 laser capture confocal microscope.

\section{T-Cell Proliferation Assay}

CD11c + cells were purified by MACS purification from infected airway luminal and granuloma cells. CD3+ T cells were purified from the spleen of BCG-infected mice and labeled with CFSE as described above. APCs and T cells were combined at a ratio of $1 \mathrm{CD} 11 \mathrm{c}+$ cell to 10 CFSE-labeled T cells for a total of $2 \times 10^{6}$ cells per well cultured for 72 hours at $37^{\circ} \mathrm{C}$ and $5 \% \mathrm{CO}_{2}$ in complete RPMI. After culture, cells were blocked for nonspecific binding of their Fc receptors with anti-CD16/CD32 for 15 minutes on ice, and then stained with $\mathrm{mAb}$ against $\mathrm{CD} 3$ and CD4. Stained cells were run on the LSRII (BD Biosciences) flow cytometer using FACSDiva software and data were analyzed with Flowjo software (Tree Star, Ashland, OR). The dilution of CFSE on CD3+CD4 ${ }^{+}$cells was assessed as an indication of T-cell proliferation.

Immunohistochemical and Immunofluorescence Staining for Localization of CD11c+ and CD11b+ APCs

For immunohistochemical staining, lungs were removed and placed in OCT compound, at which time they were stored at $-70^{\circ} \mathrm{C}$ until sectioning. Frozen tissue sections were mounted on slides and fixed with cold acetone for 15 minutes. After fixation, sections were washed with Tris-buffered saline and covered with 2\% BSA for 20 minutes at room temperature to block non-specific binding. Sections were then blocked with $\mathrm{H}_{2} \mathrm{O}_{2}$ and avidin/ biotin block (Vector Laboratories, Burlington, ON, Canada). Tissues were covered with hamster anti-mouse CD11C and on a separate occasion with rat anti-mouse CD11b mAb (BD Pharmingen, Mississauga, ON, Canada) overnight at room temperature. Sections were then incubated for 1 hour with a secondary biotinylated antihamster or anti-rat $A b$, after which sections were incubated with streptavidin HRP for 45 minutes. Slides were then incubated with 3-amino, 9 ethyl-carbozole (AEC) chromogen solution for 30 minutes, rinsed, and counterstained with hematoxylin.

For immunofluorescence staining, lungs were removed and placed in OCT compound, at which time they were stored at $-70^{\circ} \mathrm{C}$ until sectioning. Cold acetone-fixed, 5 $\mu \mathrm{mol} / \mathrm{L}$ sections were washed and treated with $3 \%$ goat serum in PBS for 30 minutes to block nospecific binding. Sections were then washed and stained with primary antibodies for CD11c (hamster anti-mouse, overnight) and CD11b (rat anti-mouse, 1 hour). Sections were subsequently washed and incubated with secondary antibodies toward the primary CD11c hamster anti-mouse (Alexfluor 488 conjugated goat anti-hamster) and CD11b rat anti-mouse (Alexafluor 633 conjugated goat anti-rat). (Molecular Probes, Invitrogen, Burlington, ON, Canada) for 1 hour at room temperature. Slides were mounted with Vectashield mounting media (Vector Laboratories) with SYTO 83 (Molecular Probes) and visualized using the Carl Ziess LSM 510 confocal microscope and images were analyzed using LSM510 image software.

\section{Statistical Analysis}

Statistical analysis was performed using unpaired, onetailed or two-tailed Student's $t$-test with Excel spreadsheet software (Microsoft Corporation, Redmond, WA). Values of $P<0.05$ were considered to be statistically significant. The one-tailed Student's $t$-test was used to analyze the information of colony forming units, whereas the two tailed Student's $t$-test was used to analyze all other values.

\section{Results}

\section{Similar Immune Cellular Composition Observed in Airway Lumen and Granuloma in Mycobacterial Infection}

After mycobacterial infection, two major APC populations are primarily infected: the alveolar macrophage and the alveolar dendritic cell. These two populations share similar cell surface makers and are broadly defined by their expression of complement receptors: CR3(CD11b/CD18) and CR4(CD11c/CD18). ${ }^{31}$ Thus we first examined the tissue localization and accumulation of CD11b+ and CD11c+ cells in mycobacterium-infected lung by immunohistochemistry. By day 21 , there was a large accumulation of both CD11b+ and CD11c + cells in the lung, with the CD11b + cells being more abundant in the granuloma (Figure 1A). As one of the pulmonary interstitial dendritic cell subsets expresses both CD11b and CD11c, ${ }^{28,32}$ we next examined the double-positive APCs in the granuloma by confocal microscopy. Confocal microscopic examination reveals mostly singly CD11c+ or CD11b + cells, and again there was a greater number of the latter in the granuloma (Figure 1B), reaffirming the results by immunohistochemistry. The frequency of CD11c $+\mathrm{CD} 11 \mathrm{~b}+$ double positive cells was found to be low (Figure 1B). Both $\mathrm{CD} 11 \mathrm{c}+$ and CD11b + APC populations increased to a maximum by day 35 and slowly declined, returning to levels similar to those in naïve mice by day 75 (data not shown).

To gain further insight into different specific immune cell types recruited to the lung after mycobacterial infection, cells contained within the airway lumen were isolated by bronchoalveolar lavage, and the granuloma cells were isolated from the lung paranchyma. ${ }^{23,24,26}$ 
A

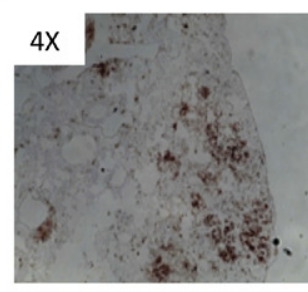

$\mathrm{CD} 11 \mathrm{c}+$

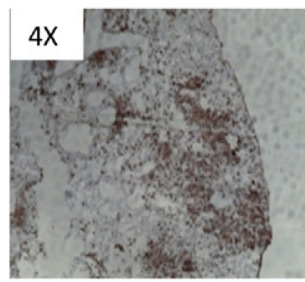

$\mathrm{CD} 11 \mathrm{~b}+$
B

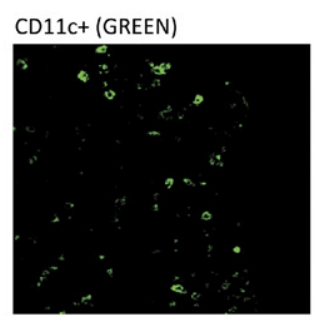

CD11c+

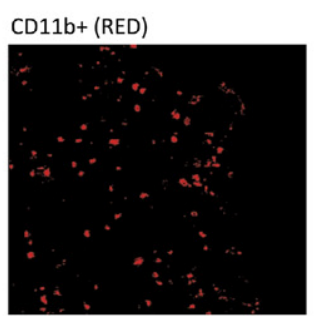

$\mathrm{CD} 11 \mathrm{~b}+$
$\mathrm{CD} 11 \mathrm{c}+\mathrm{CD} 11 \mathrm{~b}+(\mathrm{ORANGE})$

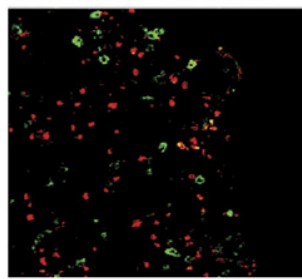

Overlay

Figure 1. Localization and accumulation of $\mathrm{CD} 11 \mathrm{c}+$ and $\mathrm{CD} 11 \mathrm{~b}+\mathrm{APCs}$ in the lung after mycobacterial infection. Infected mice were sacrificed at day 21. A: Immunohistochemical staining of mycobacterial infected lungs for CD11c- and CD11b-positive cells. B: Immunofluorescent confocal microscopy of murine mycobacterial infected lungs and demonstration of CD11c (green), CD11b (red), and overlay (orange) positive cells. Images are representative of three sets of stained sections.

Purified airway luminal and granuloma cells were stained with antibodies against CD3, CD4, CD8, CD19, CD11c, Gr.1, CD11b, or NK1.1 and analyzed by FACS. The FACS analysis revealed the presence of $\mathrm{CD} 3+\mathrm{CD} 4^{+}$ (CD4 T cells), CD3+CD8+ (CD8 T cells), CD3-CD19+ (B cells), CD3-NK1.1+ [natural killer (NK) cells], CD11c+$\mathrm{CD} 11 \mathrm{~b}+/-(\mathrm{CD} 11 \mathrm{c}+\mathrm{APCs}), \mathrm{CD} 11 \mathrm{c}-\mathrm{CD} 11 \mathrm{~b}+(\mathrm{CD} 11 \mathrm{~b}+$ APCs), and CD11c-Gr.1+ (neutrophils) cell populations in both the airway lumen and granuloma (Table 1). T and B lymphocytes and CD11c+ and CD11b+ APCs (macrophages and dendritic cells) were found to represent the majority of inflammatory cells recruited to both the airway lumen and the granuloma. The overall frequencies of inflammatory cells were highly comparable between the airway lumen and granuloma (Table 1). The greater ratio of CD11c$\mathrm{CD} 11 \mathrm{~b}+\mathrm{APC}$ versus CD11c + APCs is in agreement with the data by immunohistochemistry and confocal microscopy (Figure 1, A and B). These two APC populations most likely represent macrophages and myeloid dendritic cells, respectively. There were also many more $\mathrm{CD} 4^{+} \mathrm{T}$ cells than CD8 $+\mathrm{T}$ cells in both the airway lumen and granuloma compartments, supporting the notion that the former is the major effector T-cell subset involved in host defense during mycobacterial infection. ${ }^{12,33,34}$ Together, these data reveal a similar immune cellular profile in the airway lumen and the granuloma after pulmonary mycobacterial infection, and indicate that macrophages, dendritic cells, and T cells are the predominant antimycobacterial cellular components.

Table 1. Immune Cellular Profile of the Airway Lumen and Granuloma of Mycobacterium-Infected Mice

\begin{tabular}{lrc}
\hline \multicolumn{1}{c}{ Cell surface marker } & $\begin{array}{c}\text { Airway lumen } \\
(\% \pm \mathrm{SE})\end{array}$ & $\begin{array}{c}\text { Granuloma } \\
(\% \pm \mathrm{SE})\end{array}$ \\
\hline CD3+ & $31.97 \pm 3.71$ & $29.87 \pm 3.3$ \\
CD3+CD4 & \\
CD3+CD8+ & $17.46 \pm 5.16$ & $17.51 \pm 3.7$ \\
CD3-CD19+ & $9.65 \pm 2.99$ & $7.09 \pm 1.87$ \\
CD3-NK1.1+ & $12.51 \pm 3.22$ & $15.51 \pm 4.17$ \\
CD3-CD11c+CD11b+/- & $1.77 \pm 0.11$ & $4.05 \pm 0.7$ \\
CD3-CD11c-CD11b+ & $25.59 \pm 2.38$ & $14.82 \pm 2.73$ \\
GR1+CD11b+/- & $18.13 \pm 2.13$ & $30.08 \pm 3.99$ \\
\hline
\end{tabular}

Inflammatory cells were isolated from the airway lumen and granuloma of mycobacterium-infected lungs and stained with various leukocyte surface cell markers. Results are expressed as the cumulative average percent of total cells SEM from five independent experiments.

\section{Differential Pro-Inflammatory and Anti-Inflammatory Molecules Are Produced by Total Airway Lumen and Granuloma Inflammatory Cells during Mycobacterial Infection}

Having observed a similar overall cellular immune profile within the airway lumen and granuloma, we next began to examine the functionality of the immune cells from these two compartments. We first compared cytokine production by total inflammatory cells isolated from these two compartments. In this regard, we focused on the two type 1 cytokines, TNF- $\alpha$ and IFN- $\gamma$, that are known to play key roles in host defense against mycobacterial infection. ${ }^{11,12,14}$ On stimulation with live mycobacteria, total airway luminal cells produced significantly greater amounts of TNF- $\alpha$ compared with total granuloma cells after 12-, 24-, or 48-hour culture (Figure 2A). Similarly, airway luminal cells produced significantly higher levels of IFN- $\gamma$ than granuloma cells on stimulation with granuloma cells, producing nearly undetectable levels of this cytokine after 12-, 24-, or 48-hour culture (Figure 2B). In light of decreased proinflammatory cytokines TNF- $\alpha$ and IFN- $\gamma$ by granuloma cells (Figure 2, A and B), we evaluated the level of $\mathrm{NO}$, a critical mycobactericidal and phagosome maturationstimulating biochemical product produced by infected alveolar macrophages and dendritic cells. ${ }^{32,35,36}$ On stimulation with mycobacteria, airway luminal cells produced markedly increasing levels of NO over 12-, 24-, and 48-hour culture (Figure 2C). In sharp contrast, stimulated granuloma cells produced much lower levels of NO, which were hardly inducible over the 12 hours (Figure 2C).

Given the depressed type 1 immune phenotype seen in the granuloma, we examined the potential immune mechanism. Evidence in the literature suggests that mycobacterial infection can induce the production of IL$10,{ }^{37-39}$ which is a critical immune regulatory cytokine. We thus examined whether granuloma cells produced the immune regulatory cytokine $\mathrm{IL}-10$ and compared its level with that by airway luminal cells. In contrast to their much-heightened production of pro-inflammatory cytokines, airway luminal cells produced little $\mathrm{IL}-10$ in response to mycobacterial stimulation, whereas granuloma 
A

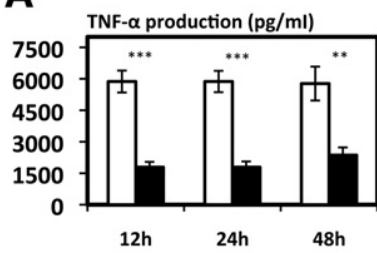

C

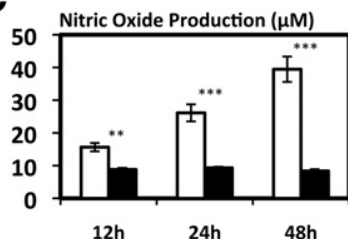

B

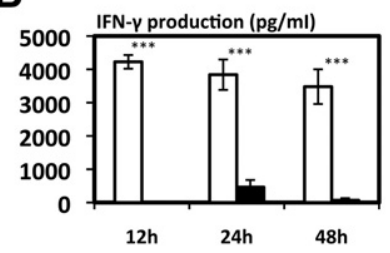

D

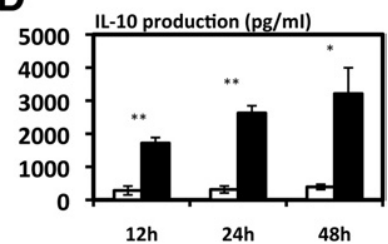

Figure 2. Production of pro-inflammatory and anti-inflammatory molecules by total airway luminal and granuloma cells. Cytokines and NO were measured by ELISA or a chemical assay in supernatants collected from cell cultures stimulated with live mycobacteria. A: TNF- $\alpha$ production by granuloma (filled bar) and airway luminal (open bar) cells. B: IFN- $\gamma$ production by granuloma and airway luminal cells. C: Nitric oxide production by granuloma and airway luminal cells. D: IL-10 production by granuloma and airway luminal cells. Data are expressed as the average values \pm SEM of three sets of cell preparations (three mice/set) and four independent experiments. ${ }^{*} P<0.05,{ }^{* * *} P<0.01,{ }^{* * * *} P<0.001$ as compared with the corresponding granuloma or airway luminal cells. h, hours; TNF- $\alpha$, tumor necrosis factor- $\alpha$; IFN- $\gamma$, interferon- $\gamma$.

cells produced significantly higher levels of IL-10 over the entire course of culture (Figure 2D). As it was shown that IL-10 could suppress Th17 cells and the production of $\mathrm{IL}-17,{ }^{40,41}$ we examined the levels of $\mathrm{IL}-17$ in the culture supernatant of airway luminal and granuloma cell cultures. Indeed, airway luminal cells produced larger amounts of IL-17 than granuloma-derived cells (Table 2).

To address whether the granuloma represents a generalized immune suppressed environment, we compared the production of chemokines by airway luminal and granuloma cells. To this end, we focused on measuring the chemokines involved in neutrophil, APC, and lymphocyte chemotaxis: keratinocyte chemoattractant, monocyte chemoattractive protein-1, and macrophage inflammatory protein-1 $\beta$. Of interest, compared with airway luminal cells, granuloma cells produced similar or even increased levels of chemokines (Table 2), in contrast to their much-reduced production of type 1 cytokines (Figure 2, A and B).

Together, the above data indicate that, first, compared with the airway lumen, the granuloma represents a differentially regulated immune environment with greatly reduced type 1 cytokines but yet similar or increased chemokine responses; and second, the reduced type 1 immune activation in the granuloma is associated with markedly enhanced production of immune suppressive cytokine IL-10.

\section{Differential Pro-Inflammatory and} Anti-Inflammatory Molecules Are Produced by $C D 11 b+$ and $C D 11 c+A P C$ Populations of

\section{Airway Lumen and Granuloma during}

\section{Mycobacterial Infection}

Thus, despite their similar cellular composition, total granuloma cells demonstrate a suppressed type 1 im- mune phenotype with reduced cytokine and NO responses. To address the major cellular sources displaying such type 1 immune suppression, we first analyzed the major APC populations by using purified CD11c + and CD11b + cells, which are most likely dendritic cells and macrophages, respectively. ${ }^{28,42}$ Our data show that these CD11c+CD11b+/- and CD11c-/ CD11b + APCs are the most prominent APC populations in both the airway lumen and granuloma (Table 1). These cells were shown to be a significant cellular source of TNF- $\alpha$, IFN- $\gamma, \quad \mathrm{L}-10$, and $\mathrm{NO}$ in various models of pulmonary mycobacterial infection. ${ }^{36,43,44}$ Thus, we purified CD11c+CD11b+/- (CD11c+) and CD11c-/CD11b+ $(C D 11 b+)$ APC populations from total airway lumen and granuloma cells by double column-based MACS purification and assessed their cytokine and NO responses. Both airway luminal CD11c+ and CD11b+ APCs produced more TNF- $\alpha$ than their corresponding granuloma counterparts on stimulation with soluble mycobacterial antigens (m.tb CF) (Figure 3, A and E). Similarly, mycobacterium BCG-infected airway luminal CD11c+ APCs also produced more TNF- $\alpha$ than the granuloma-derived CD11c+ APCs. In comparison, airway luminal CD11b+ cells produced similar amounts of TNF- $\alpha$ as the granuloma-derived CD11b + APCs (Figure 3, A and E). Both airway luminal CD11c+ and CD11b + APCs produced more IFN- $\gamma$ than the corresponding granuloma counterparts on stimulation by soluble mycobacterial antigens or mycobacterial BCG (Figure 3, B and F). Of note, CD11b+ APC populations, whether airway lumen or granuloma derived, produced less TNF- $\alpha$ and IFN- $\gamma$ than CD11C+ APCs (Figure 3, B and F). Associated with reduced type 1 cytokine production by granuloma APC populations is markedly decreased NO production by both granuloma CD11c+ and CD11b+ APCs (Figure 3, C and G).

Similar to the unfractionated granuloma cells (Figure 2 ), the production of immune suppressive or anti-inflammatory cytokine IL-10 by both granuloma CD11c+ and CD11b + APC populations was significantly upregulated compared with their airway luminal counterparts (Figure 3, D and $\mathrm{H}$ ). Together the above results suggest that, relative to extragranuloma bronchoalveolar macrophages and dendritic cells, the APC populations present in mycobacterial granuloma demonstrate reduced type 1 immune activation that is associated with enhanced production of immune-suppressive IL-10.

Table 2. Cytokine and Chemokine Production Profile by Airway Lumen and Granuloma Cells

\begin{tabular}{lcc}
\hline Cytokine & $\begin{array}{c}\text { Airway lumen } \\
(\mathrm{pg} / \mathrm{mL} \pm \mathrm{SE})\end{array}$ & $\begin{array}{c}\text { Granuloma } \\
(\mathrm{pg} / \mathrm{mL} \pm \mathrm{SE})\end{array}$ \\
\hline $\mathrm{IL}-17$ & $7807.99 \pm 682.72$ & $959.94 \pm 46.16$ \\
$\mathrm{KC}$ & $18890.96 \pm 399.56$ & $14319.42 \pm 213.52$ \\
MCP-1 & $167.35 \pm 6.85$ & $1224.89 \pm 36.09$ \\
MIP-1 $\beta$ & $2325.22 \pm 160.53$ & $7982.31 \pm 203.30$ \\
\hline
\end{tabular}

Isolated total airway luminal and granuloma cells were cultured with live mycobacteria. IL-17 and chemokines in culture supernatants were assessed by luminex assay. The data are expressed as the average values \pm SEM of triplicate samples. 
CD11c+
A

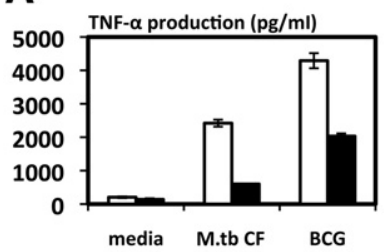

C

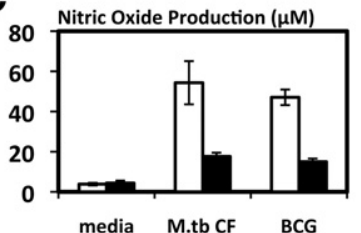

$\mathrm{CD} 11 \mathrm{~b}+$

E

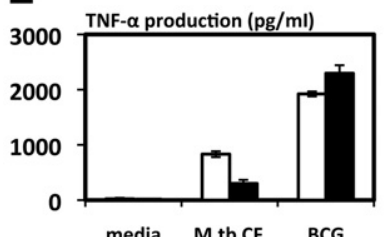

G

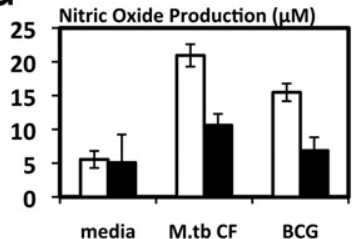

B

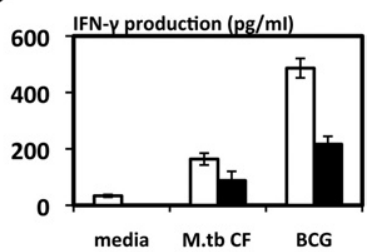

D

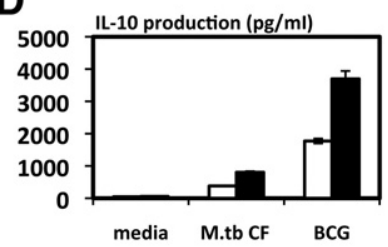

F

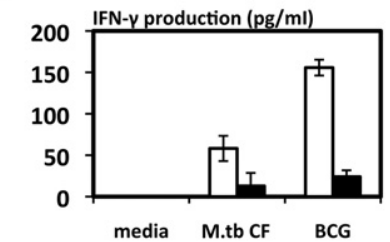

$\mathrm{H}$

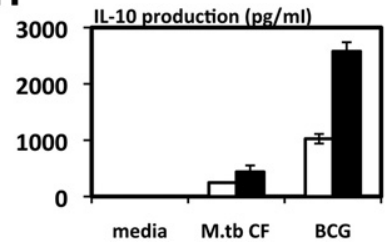

Figure 3. Production of pro-inflammatory and anti-inflammatory molecules by purified $\mathrm{CD} 11 \mathrm{c}+\mathrm{CD} 11 \mathrm{~b}+/-$ and $\mathrm{CD} 11 \mathrm{c}-\mathrm{CD} 11 \mathrm{~b}+\mathrm{APCs}$ from airway lumen and granuloma. APC populations were purified from total airway luminal and granuloma cells. Cytokines and NO were measured by ELISA or a chemical assay in the supernatants of cell cultures with or without stimulation by soluble mycobacterial antigens m.tb-CF or live mycobacteria. A and E: TNF- $\alpha$ production by airway luminal (open bar) or granuloma cells (filled bar). B and F: IFN- $\gamma$ production by airway luminal or granuloma cells. $\mathbf{C}$ and $\mathbf{G}$. Nitric oxide production by airway luminal or granuloma cells. $\mathbf{D}$ and H: IL-10 production by airway luminal or granuloma cells. Data are expressed as the average values \pm SEM of triplicate samples obtained from nine pooled mice, representative of two independent experiments. h, hours; TNF- $\alpha$, tumor necrosis factor- $\alpha$; IFN- $\gamma$, interferon- $\gamma$; M.tb CF, mycobacterial antigens culture filtrate; BCG, Bacillus Calmette-Guerin.

\section{Granuloma-Derived APCs Have Reduced Capacity to Phagocytose Mycobaceria}

Given the suppressed type 1 immune profile displayed by mycobacterial granuloma-derived APC populations, we investigated whether this suppressed immune profile might lead to altered antimycobacterial activities of APCs. To this end, we assessed the ability of granulomaderived CD11c+ and CD11b+ APCs to phagocytose fluorescence-labeled mycobacterium BCG as analyzed by FACS. Compared with airway luminal CD11c+ and CD11b + APCs, granuloma-derived APCs showed a reduced capacity to phagocytose fluorescence-labeled mycobacteria (airway lumen CD11c $+26.2 \%$, CD $11 b+$ $34.7 \%$ vs granuloma CD11c $+10.6 \%$, and CD11b + $17.4 \%$, respectively) (Figure 4). This observation was
Airway Lumen

Granuloma

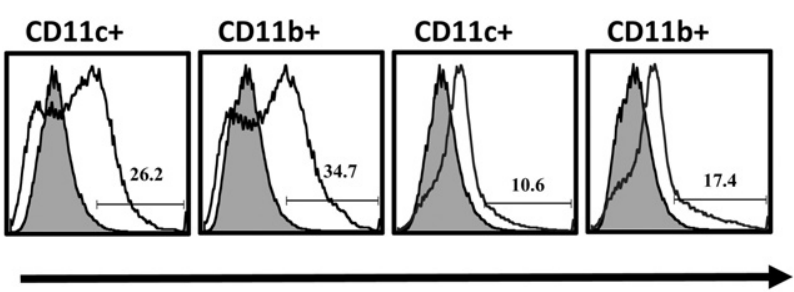

BCG-CFSE

Figure 4. Differential phagocytosis rate of mycobacteria by airway luminal and granuloma derived APC populations assessed by FACS. Purified APCs from the airway lumen and granuloma were incubated with CFSE fluorescence-labeled mycobacteria, and phagocytosis rates were assessed by gating on CFSE + CD11c+ and CD11b+ APCs. Histograms are representative of duplicate cultures obtained from nine pooled mice and two independent experiments. BCG, Bacillus Calmette-Guerin; CFSE, 5,6-carboxyfluorescein diacetate succinimidyl ester.

supported by using confocal microscopy, which showed a lower intensity of fluorescence-labeled mycobacteria uptake by granuloma-derived CD11c+ APCs when compared with airway luminal CD11C+ APCs (Figure 5). These data suggest that reduced type 1 immune activation within granuloma can lead to diminished antimycobacterial function of granuloma APCs.

Given the impaired ability of granuloma APCs to uptake mycobacteria (Figures 4 and 5) and their diminished type 1 cytokine responses (Figure 3), we questioned whether these APCs might also have reduced ability to drive T-cell proliferation. To this end, airway luminal and granuloma APCs were paired with splenic CFSE-labeled CD4 T cells, and the level of T-cell proliferation was evaluated by the extent of CFSE dilution. We found that granuloma-derived APCs showed an approximately $40 \%$ reduced capacity to drive ex vivo CD4 ${ }^{+}$T-cell proliferation compared with airway luminal APCs (Figure 6).

\section{Airway Lumen Granuloma}
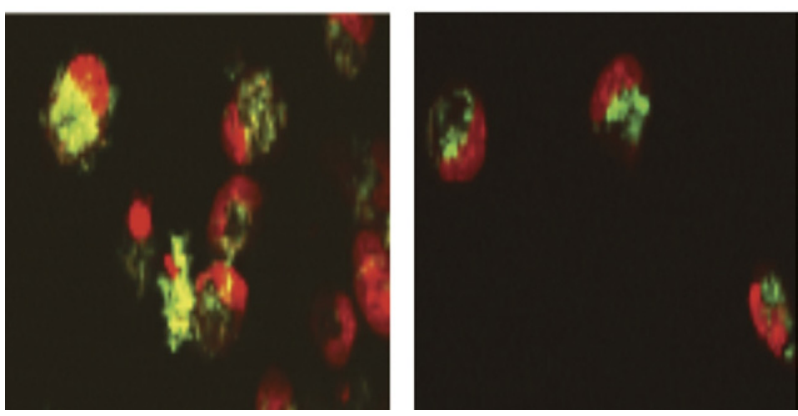

Figure 5. Differential phagocytosis of fluorescence-labeled mycobacteria by airway luminal and granuloma derived APCs visualized by confocal microscopy. Purified APCs from the airway lumen and granuloma of mycobacterium-infected mice were incubated with opsonized fluorescence-labeled mycobacteria. After incubation, cells were fixed and stained for the localization of the nucleus (red) and the uptake of fluorescence-labeled mycobacteria (green). Uptake of fluorescence-labeled mycobacteria was assessed by laser scanning confocal microscopy. Cells were isolated from nine pooled mice. 


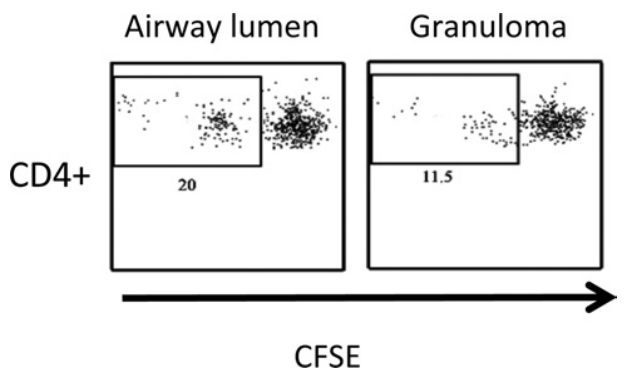

Figure 6. Differential $\mathrm{CD} 4{ }^{+} \mathrm{T}$-cell proliferation stimulated by airway luminal and granuloma APCs. Airway luminal or granuloma derived APCs purified from mycobacterium-infected mice were paired with 5,6-carboxyfluoresceindiacetate-succinimidyl-ester-labeled (CFSE) splenic T cells and cultured for proliferation analysis. Proliferation was assessed by the CFSE dilution of $\mathrm{CD} 3+\mathrm{CD}^{+}{ }^{+} \mathrm{T}$ cells assessed by flow cytometry using $\mathrm{CD} 3+\mathrm{CD} 4^{+}$gating. Dot plots are representative of quadruplicate samples per condition obtained from nine pooled mice.

\section{Differential Pro-Inflammatory and} Anti-Inflammatory Cytokines Are Produced by T Cells of Airway Lumen and Granuloma during Mycobacterial Infection

It is known that, after mycobacterial infection, activated type $1 \mathrm{~T}$ cells, particularly those of the $\mathrm{CD} 4^{+}$subset, are the most abundant cellular source of IFN- $\gamma$, which is a signature type 1 cytokine. ${ }^{33,44,45} \mathrm{It}$ is believed that infected APCs and T cells interact and reciprocally affect each other's activation. Having observed a suppressed type 1 immune phenotype of APCs in the granuloma, we next examined its impact on T-cell activation in the granuloma compared with the $T$ cells present in the airway lumen by using intracellular cytokine staining. To this end, total cells isolated from the airway lumen and granuloma were stimulated with mycobacterial antigens, stained for T-cell surface markers and intracellular IFN- $\gamma$ and IL-10, and analyzed by flow cytometry. There was clearly a much greater portion of total airway luminal CD4 T cells responding to mycobacterial antigen stimulation by producing IFN- $\gamma(6.5 \%$ of CD4 T cells) compared with granuloma $T$ cells (3.27\% of CD4 T cells) (Figure 7 ). In addition to CD4 T cells, granuloma CD8 T cells also showed a lower level of IFN- $\gamma$ positivity, indicating a global suppression of T-cell responses (data not shown). In contrast to their markedly reduced IFN- $\gamma$ responses, granuloma CD4 T cells displayed markedly increased IL-10 production ( $4.61 \%$ in granuloma vs $0.41 \%$ in the airway lumen) (Figure 7). Together with the data on APC populations (Figure 3), these results reveal that, first, both APCs and CD4 T cells are significant cellular sources of type 1 cytokines in mycobacterium-infected lung; and second, in keeping with the suppressed type 1 activation of granuloma APC populations, the type 1 mycobacterial antigen-specific T cells present within granuloma are also phenotypically altered with reduced type 1 cytokine production and increased immune-suppressive IL-10 production, relative to those present in the extragranuloma, bronchoalveolar environment of the same mycobacterium-infected host.

\section{Increased IL-10 Contributes to Suppressed Type 1 Immune Activation in Granuloma Microenvironment}

Thus far we have established an inverse functional relationship between type 1 immune activation and IL-10 production in the airway lumen and granuloma of mycobacterium-infected lung. This suggests the involvement of heightened IL-10 expression in immune suppression within granuloma. To investigate the role of IL-10 in immune regulation in the airway luminal and granuloma environments, we infected both wild-type (wt) and IL-10 knockout (IL-10KO) mice with mycobacteria and purified airway luminal and granuloma cells. First, we compared the level of activation of type 1 CD4 T cells derived from the airway lumen and granuloma of wt and IL-10KO mice. Consistent with the data presented in Figure 7 , there was a much smaller frequency of IFN- $\gamma$-producing CD4 T cells $(2.86 \%)$ in the granu-
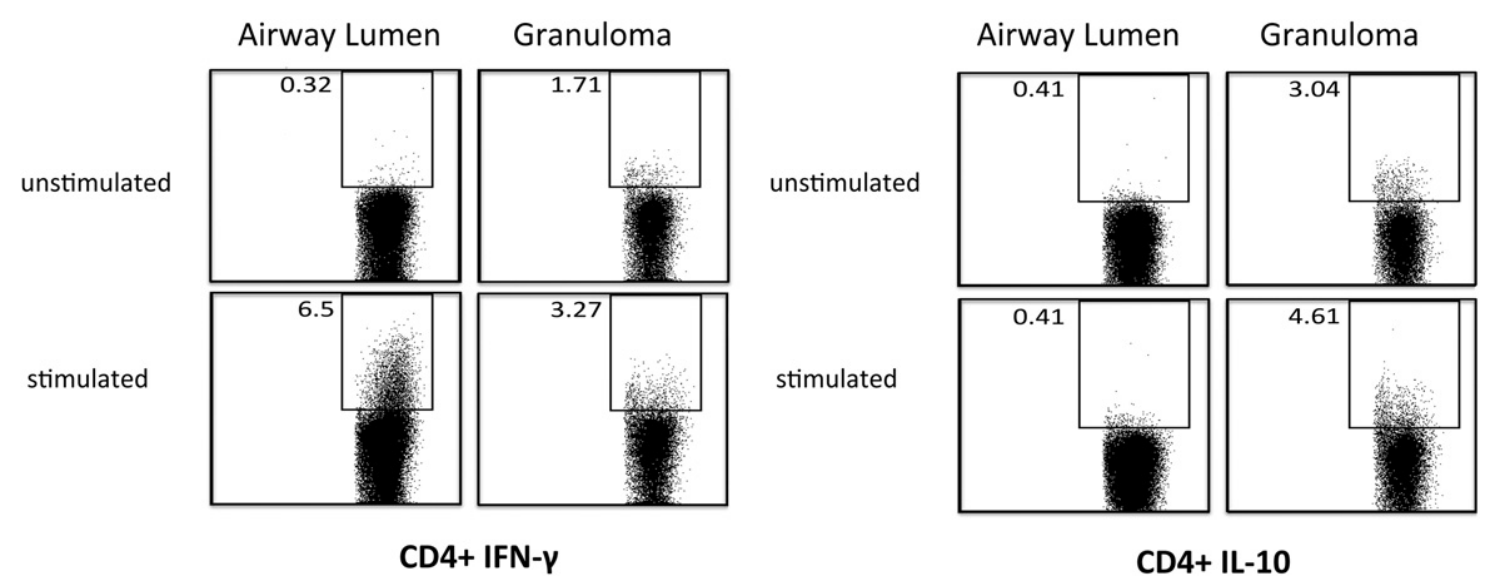

Figure 7. Suppressed antigen-specific type 1 immune activation and enhanced IL-10 responses in granuloma CD 4 T cells. Total cells isolated from the airway lumen and granuloma of mycobacterium-infected mice were cultured with or without stimulation by mycobacterial antigens and subject to cell surface and intracellular cytokine staining and flow-cytometric analysis. Dot plots are representative of three sets of cell preparations (each set of cell preparation was pooled from three mice) and three independent experiments. IFN- $\gamma$, interferon- $\gamma$. 

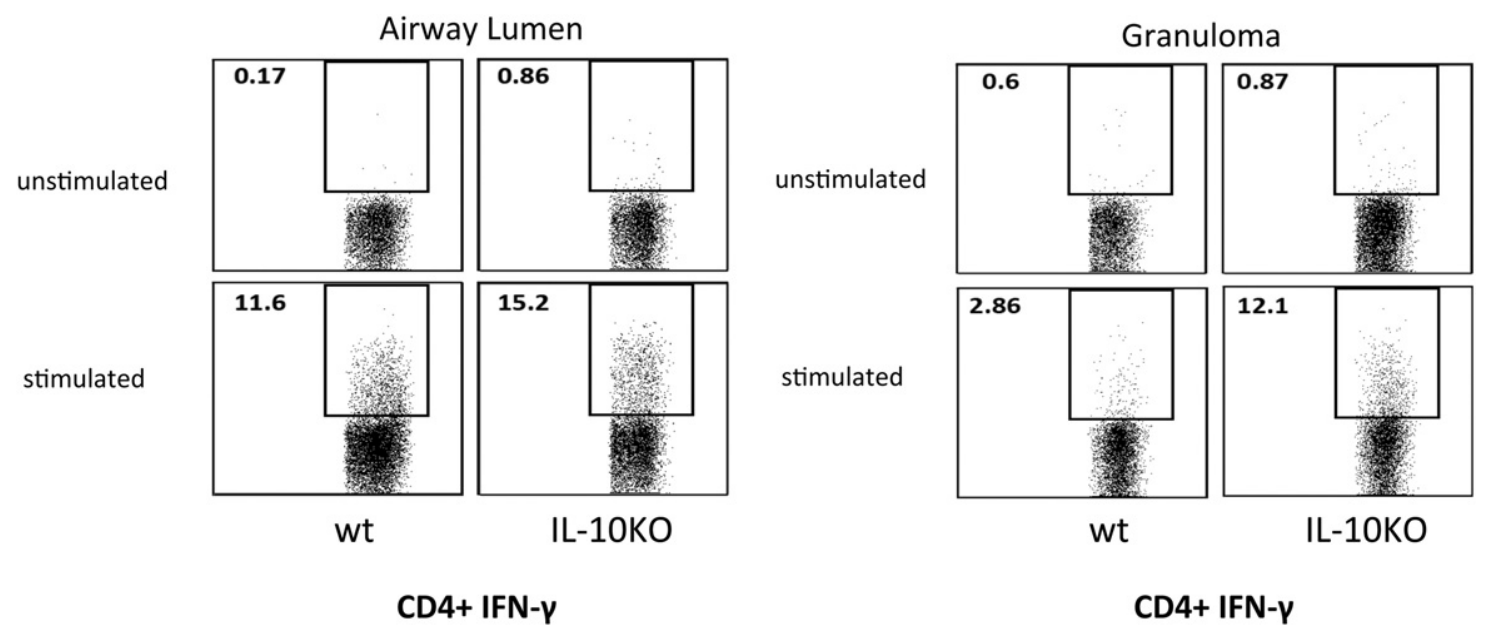

Figure 8. Restored type 1 immune activation of granuloma CD4 T cells by removal of IL-10. Total cells isolated from the airway lumen and granuloma of mycobacterium-infected wild-type (wt) and IL-10 knock-out (KO) mice were cultured with or without stimulation by mycobacterial antigens and subject to cell surface and intracellular cytokine staining and flow cytometry. Dot plots are representative of three sets of cell preparations (each set of cell preparation was pooled from three mice). IFN- $\gamma$, interferon- $\gamma$.

loma of wt hosts than in the airway lumen (11.6\%) of wt hosts (Figure 8). However, lack of IL-10 remarkably restored the level of IFN- $\gamma$ responses in granuloma CD4 T cells (from $2.86 \%$ to $12.1 \%$ ), which is comparable to $11.6 \%$ positivity found in wt airway luminal CD4 T cells (Figure 8). In comparison, the lack of IL-10 had a much smaller impact on IFN- $\gamma$-producing CD4 T cells in the airway lumen (from wt $11.6 \%$ to $15.2 \%$ ) (Figure 8 ), in keeping with relatively little IL-10 protein produced by airway luminal APCs and T cells (Figures 2, 3 , and 7 ).

Furthermore, we examined the production of IFN- $\gamma$ by total airway luminal and granuloma cells. Again, in keeping with the data in Figure 2, wt granuloma cells produced much less IFN- $\gamma$ than wt airway luminal cells (Figure 9A). However, lack of IL-10 markedly restored IFN- $\gamma$ production by granuloma cells from approximately $500 \mathrm{pg}$ up to $8000 \mathrm{pg} / \mathrm{mL}$, which is comparable to that produced by wt airway luminal cells $(9000 \mathrm{pg} /$ $\mathrm{mL}$ ) (Figure 9A). In comparison, lack of IL-10 only modestly further enhanced IL-10 production by airway luminal cells (from 9000 to $13,000 \mathrm{pg} / \mathrm{mL}$ ) (Figure 9A). The above results indicate that enhanced IL-10 responses within the granuloma account significantly for the markedly suppressed type 1 immune activation.

To evaluate the impact on antimycobacterial activities of enhanced type 1 immune activation in the mycobacterial graunloma of IL-10KO hosts, we assessed the total mycobacterial burden in the lungs of WT and IL-10KO mice. Indeed, in keeping with markedly improved type 1 immune activation in granuloma of IL$10 \mathrm{KO}$ hosts, the total bacterial counts were found to be significantly lower in the lungs of these mice when compared to wt counterparts (Figure 9B). Together the above results indicate that enhanced IL-10 production accounts not only for suppressed type 1 immune activation but also for decreased antimycobacterial activities.

\section{Discussion}

The formation of the granuloma is considered a crucial event in host defense against pulmonary mycobacterial

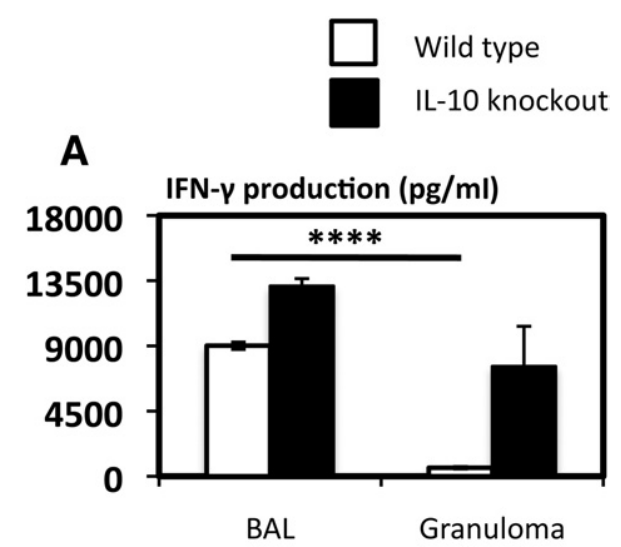

B

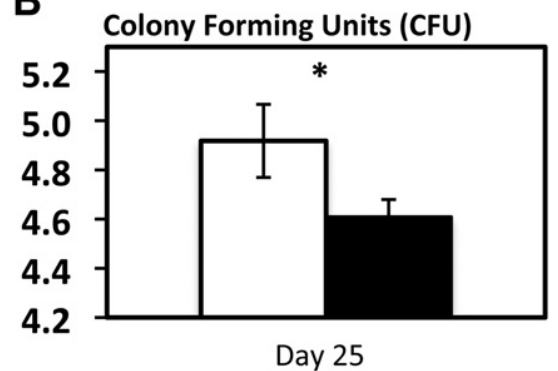

Figure 9. Restored type 1 immune activation of granuloma cells and enhanced antimycobacterial host defense by removal of IL-10. A: Total cells were isolated from the airway lumen and granuloma of mycobacteriuminfected wild-type (wt) and IL-10 knockout mice and cultured with stimulation by live mycobacteria. Culture supernatants were measured for interferon- $\gamma($ IFN- $\gamma)$ protein content by ELISA. BAL, brochoalveolar lavage cells. B: Lung homogenates from mycobacterium-infected wt or IL-10 knockout mice were subject to a mycobacterial CFU assay. Values displayed in $\mathbf{A}$ are average values \pm SEM of three sets of cell preparations. Values in $\mathbf{B}$ are expressed as average values \pm SEM of nine mice/group. ${ }^{*} P<0.05$, as compared with IL-10KO group; ${ }^{* \text { *a*** }} P<0.0001$ as compared with wt granuloma. 
infection. Despite the importance of granuloma formation and integrity to antimycobacterial host defense, ${ }^{10,46}$ little is understood about why the mycobacterium is able to paradoxically survive within the intact granuloma for a long time. Although recently emerging evidence has begun to suggest a symbiotic nature of mycobacterial granuloma, it remains unclear whether the granuloma environment is immune suppressed relative to the tissue environment outside of granuloma and, if so, what are the underlying immune mechanisms.

We and others have documented that the successful control of mycobacteria is mediated largely through the interaction of activated $T$ lymphocytes with infected APCs. ${ }^{6,36,44}$ The ability of the host to control mycobacteria is dependent on the ability of recruited T cells, specifically type 1 polarized CD4 T cells, to secrete IFN- $\gamma$ and activate the intracellular killing mechanisms of the infected APCs. ${ }^{3,36}$ Although the two main APC populations, macrophages and dendritic cells, can be readily infected by mycobacteria, macrophages are better equipped to control internalized mycobacteria, primarily through the production of NO. ${ }^{47}$ On the other hand, infected dendritic cells are better able to activate and polarize CD4 T cells through the production of type $1 \mathrm{im}$ mune cytokines such as IL-12. ${ }^{47}$ Both macrophage and dendritic cell populations provide an essential link between the innate and the adaptive immune systems that may be subject to the exploitation by mycobacteria after infection.

Mounting evidence indicates the importance of examining immune responses in different lung compartments, particularly the airway luminal space and the parenchyma. ${ }^{1,48,49}$ Thus, in relation to pulmonary mycobacterial infection, it would be important to examine the immune responses both in the airway lumen, ie, the site of initial infection, and the granuloma, ie, the focal point of bacterial control and a site to which the majority of mycobacteria home. ${ }^{12,50}$ The granuloma is composed of a nucleus of infected macrophages along with recruited monocytes, T cells, neutrophils, and NK cells, and it is formed within the lung parenchymal tissue around the vessel and bronchi. Despite the ample information about the pivotal role of both APC and activated T-cell populations in antimycobacterial host defense, to date no study has examined and compared the phenotype and functional properties of these important immune cell populations located in the airway lumen and granuloma during pulmonary mycobacterial infection. This line of study will help to address the question whether the granuloma environment is immune suppressed relative to the tissue environment outside of the granuloma.

In the present study, we have examined and compared the phenotypic and functional characteristics of the two major immune cell populations, APCs and T cells, within the granuloma against those located in the airway luminal space outside of the granuloma. Our study reveals that, despite the largely comparable immune cellular profile in the airway lumen and granuloma compartments, the granuloma cells have adopted a suppressed type 1 immune phenotype. This is typified by lower levels of type 1 immune cytokines and mycobactericidal NO and higher levels of immune suppressive IL-10, compared with airway luminal cells. In addition, this is the case for both granuloma APCs (CD11c+ dendritic cells and CD11b + macrophages) and mycobacterial antigenspecific $T$ cells. As a result, the antimycobacterial and T-cell-activating activities of granuloma APCs are compromised. Of note, the host immune responses are only selectively suppressed in the granuloma, as we found the chemokine responses within the granuloma to be largely intact or even more intense than the extragranuloma environment, in keeping with the high demand for continual recruitment of inflammatory cells into the granuloma. ${ }^{34}$ Although chemokine responses were similar or elevated in the granuloma, IL-17 responses were decreased, paradoxical to the current belief that IL-17 is involved in the induction of chemokines in some experimental models. ${ }^{40,51}$ This provides further support that the granuloma is a differentially regulated immune environment because of the heavy presence of mycobacteria, a phenomenon that likely evolves over the course of the infection. Of importance, we further demonstrated a critical role of enhanced IL-10 in mediating suppressed type 1 immune activation within the granuloma, as the lack of IL-10 restored type 1 immune responses in the granuloma, whereas it had a minimal effect on airway luminal immune responses. Based on these findings, we believe that the high concentration of mycobacteria and the intimate nature, ie, the close proximinity of infected APCs and adaptive cellullar immune components, account for the immune-suppressive environment in the granuloma relative to the extragranuloma environment. Thus our study has revealed, for the first time, an immune suppressive nature of mycobacterial granuloma. The study findings suggest that, in contrast to the traditional belief, the granuloma environment represents an immunological niche that may paradoxically favor the persistence of mycobacteria. Given that many mycobacterial species are notoriously difficult to eliminate, our current findings provide a plausible mechanism to explain why mycobacterial infections such as M.tb can remain latent for a lifetime in the lung of otherwise healthy, immune-competent human beings. ${ }^{7-9}$

It is noteworthy that we used an attenuated strain of mycobacteria ( $M$. bovis BCG), but not virulent $M$.tb, in our current study. The current physical and technical constrains in our level III biohazard containment facility does not allow us to carry out the elaborate procedures needed for isolating bronchoalveolar and granuloma cells from M.tb-infected lungs. However, after pulmonary BCG or M.tb infection in mice, the overall kinetics and cellular makeup of the granuloma are comparable between models of BCG and M.tb infection. ${ }^{11,12,42,52}$ Furthermore, the critical role of type $1 \mathrm{~T}$-cell immunity, including the role of CD4 T cells and type 1 cytokines in antimycobacterial host defense, has shown to be true for pulmonary infection elicited by exposure to either BCG or M.tb. ${ }^{11,}{ }^{12},{ }^{53-57} M$. bovis BCG also uss similar immune evasion strategies as M.tb to dampen host immune activation mechanisms including intracellular persistence, ${ }^{58-60}$ inhibiting $\mathrm{MHC}$ molecule expression, ${ }^{42,61}$ and inducing IL-10 production. ${ }^{37-39,62}$ Despite these described similarities, we must caution that, compared with 
$\mathrm{BCG}, M$.tb is a significantly more virulent and persistent pathogen. For instance, in the absence of TNF- $\alpha$, infection with either BCG or M.tb will result in mortality, but the onset of mortality is seen earlier after M.tb infection. ${ }^{11,55}$ Similarly, whereas infection with either BCG or M.tb in the absence of TLR2 or TLR4 results in enhanced bacterial burden, it occurs to a higher magnitude after M.tb infection. ${ }^{63,64}$ Thus, given the difference in virulence between $M$. bovis BCG and M.tb, the findings from our current study will need to be independently verified in a model of pulmonary M.tb infection when it becomes technically possible in the future.

Although our current study carries a focus on the host mechanisms, based on some recent evidence, ${ }^{16}$ it is plausible to speculate that mycobacteria have adopted the mechanisms to fully parasitize the granuloma in an attempt to evade host-mediated clearance, and that some of these mechanisms may involve the works of the mycobacterial "persistence" gene products. ${ }^{16,17}$ Many parallels exist between the granuloma and other immuneevasive microenvironments, such as those within tumors. The ability of the tumor to shield itself from immune infiltration is mediated by using many mechanisms similar to those seen after the formation of mycobacterial granuloma. Specifically, many tumors as well rely on the induction of IL-10 and other immune suppressive cytokines to dampen type 1 immune responses and to remain immune evasive. ${ }^{65}$ In a fashion similar to that of the tumor, although it is believed that mycobacteria may simultaneously use multiple mechanisms of immune evasion including mechanisms of down-regulating antigen presentation, ${ }^{42,61}$ in the current study we have shown that IL-10 is one of the essential mechanisms through which the immune suppressive environment of mycobacterial granuloma is maintained. Despite the overwhelming evidence to support a direct role of mycobacterial infection in inducing IL-10 production by APCs, ${ }^{37-39,62}$ it is plausible for us to consider the possibility that some level of IL-10 may be actively induced as part of host immune regulatory mechanisms as a means to limit immunopathology, a concession that could be exploited by mycobacteria and has recently been suggested by others. ${ }^{66}$ Although our current findings and a large body of literature information support the immune suppressive role of IL-10 in mycobacterial infection, one study shows the addition of exogenous IL-10 to enhance macrophage activation. ${ }^{67}$

In conclusion, our study, for the first time, has examined the profile and characteristics of granuloma APCs and $T$ cells in a model of pulmonary mycobacterial infection and compared them with those located in the extragranulomatous bronchoalveolar space of the same host. Contrary to the previous belief, we found that, within the granuloma, both APC and T-cell populations differed from their extragranuloma counterparts in that they assumed a suppressed and functionally impaired immune phenotype. Our study thus provides an important clue as to in which way granuloma may offer the mycobacterium a unique biological niche for its stand-off with the immune system.

\section{Acknowledgment}

The authors thank Mary J. Smith for technical assistance.

\section{References}

1. Jeyanathan M, Heriazon A, Xing Z: Airway luminal T cells: a newcomer on the stage of TB vaccination strategies. Trends Immunol 2010, 31:247-252

2. Flynn JL, Chan J: Immunology of tuberculosis. Annu Rev Immunol 2010, 31:247-252

3. Cooper AM: Cell-mediated immune responses in tuberculosis. Annu Rev Immunol 2009, 27:393-422

4. Hesseling AC, Rabie H, Marais BJ, Manders M, Lips M, Schaaf HS, Gie RP, Cotton MF, van Helden PD, Warren RM, Beyers N: Bacille Calmette-Guerin vaccine-induced disease in HIV-infected and HIVuninfected children. Clin Infect Dis 2006, 42:548-558

5. Primm TP, Lucero CA, Falkinham JO, 3rd: Health impacts of environmental mycobacteria. Clin Microbiol Rev 2004, 17:98-106

6. Danelishvilli L, Bermudez LE: Role of type I cytokines in host defense against Mycobacterium avium infection. Curr Pharm Des 2003, 9:61-65

7. Bold TD, Ernst JD: Who benefits from granulomas, mycobacteria or host? Cell 2009, 136:17-19

8. Paige C, Bishai WR: Penitentiary or penthouse condo: the tuberculous granuloma from the microbe's point of view. Cell Microbiol 12:301309

9. Co DO, Hogan LH, Kim S-I, Sandor M: Mycobacterial granulomas: keys to a long-lasting host-pathogen relationship. Clin Immunol 2004, 113:130-136

10. Saunders BM, Britton WJ: Life and death in the granuloma: immunopathology of tuberculosis. Immunol Cell Biol 2007, 85:103-111

11. Zganiacz A, Santosuosso M, Wang J, Yang T, Chen L, Anzulovic M, Alexander S, Gicquel B, Wan Y, Bramson J, Inman M, Xing Z: TNF- $\alpha$ is a critical negative regulator of type 1 immune activation during intracellular bacterial infection. J Clin Invest 2004, 113:401-413

12. Wakeham J, Wang J, Magram J, Croitoru K, Harkness R, Dunn P, Zganiacz A, Xing Z: Lack of both types 1 and 2 cytokines. Tissue inflammatory responses, and immune protection during pulmonary infection by Mycobacterium bovis Bacille Calmette-Guerin in IL-12deficient mice. J Immunol 1998, 160:6101-6111

13. Fremond CM, Yeremeev V, Nicolle DM, Jacobs M, Quesniaux VF, Ryffel B: Fatal Mycobacterium tuberculosis infection despite adaptive immune response in the absence of MyD88. J Clin Invest 2004, 114:1790-1799

14. Roach DR, Bean AGD, Demangel C, France MP, Briscoe H, Britton WJ: TNF regulates chemokine induction essential for cell recruitment Granuloma formation, and clearance of mycobacterial infection. J Immunol 2002, 168:4620-4627

15. Chiu B-C, Freeman CM, Stolberg VR, Hu JS, Komuniecki E, Chensue SW: The innate pulmonary granuloma: characterization and demonstration of dendritic cell recruitment and function. Am J Pathol 2004 , 164:1021-1030

16. Volkman HE, Pozos TC, Zheng J, Davis JM, Rawls JF, Ramakrishnan $\mathrm{L}$ : Tuberculous granuloma induction via interaction of a bacterial secreted protein with host epithelium. Science 327:466-469

17. Davis JM, Ramakrishnan L: The role of the granuloma in expansion and dissemination of early tuberculous infection. Cell 2009, 136: 37-49

18. Cosma CL, Humbert O, Sherman DR, Ramakrishnan L: Trafficking of superinfecting Mycobacterium organisms into established granulomas occurs in mammals and is independent of the Erp and ESX-1 mycobacterial virulence loci. J Infect Dis 2008, 198:1851-1855

19. Cosma CL, Humbert O, Ramakrishnan L: Superinfecting mycobacteria home to established tuberculous granulomas. Nat Immunol 2004 , 5:828-835

20. Al-Muhsen S, Casanova JL: The genetic heterogeneity of mendelian susceptibility to mycobacterial diseases. J Allergy Clin Immunol 2008, 122:1043-1051; quiz 1052-1043

21. Jacobs M, Samarina A, Grivennikov S, Botha T, Allie N, Fremond C, Togbe D, Vasseur V, Rose S, Erard F, Monteiro A, Quesniaux V, Ryffel 
B: Reactivation of tuberculosis by tumor necrosis factor neutralization. Eur Cytokine Netw 2007, 18:5-13

22. Wang J, Santosuosso M, Ngai P, Zganiacz A, Xing Z: Activation of CD8 T cells by mycobacterial vaccination protects against pulmonary tuberculosis in the absence of CD4 T cells. J Immunol 2004, 173: 4590-4597

23. Santosuosso M, Zhang $X$, McCormick S, Wang J, Hitt M, Xing Z: Mechanisms of mucosal and parenteral tuberculosis vaccinations: adenoviral-based mucosal immunization preferentially elicits sustained accumulation of immune protective CD4 and CD8 T cells within the airway lumen. J Immunol 2005, 174:7986-7994

24. Stolberg VR, Chiu BC, Komuniecki E, Freeman CM, Chensue SW: Analysis of inducible costimulatory molecule participation during the induction and elicitation of granulomatous responses to mycobacterial and schistosomal antigens. Cell Immunol 2005, 237:45-54

25. Chiu BC, Stolberg VR, Freeman CM, Chensue SW: Mononuclear phagocyte-derived interleukin-10 suppresses the innate pulmonary granuloma cytokine response in aged mice. Am J Pathol 2007, 171: 829-837

26. Freeman CM, Stolberg VR, Chiu BC, Lukacs NW, Kunkel SL, Chensue SW: CCR4 participation in Th type 1 (mycobacterial) and Th type 2 (schistosomal) anamnestic pulmonary granulomatous responses. J Immunol 2006, 177:4149-4158

27. Kugathasan K, Roediger EK, Small CL, McCormick S, Yang P, Xing Z $\mathrm{CD} 11 \mathrm{c}+$ antigen presenting cells from the alveolar space, lung parenchyma and spleen differ in their phenotype and capabilities to activate naive and antigen-primed T cells. BMC Immunol 2008, 9:48

28. Wang J, Snider DP, Hewlett BR, Lukacs NW, Gauldie J, Liang H, Xing $Z$ : Transgenic expression of granulocyte-macrophage colony-stimulating factor induces the differentiation and activation of a novel dendritic cell population in the lung. Blood 2000, 95:2337-2345

29. Santosuosso M, McCormick S, Roediger E, Zhang X, Zganiacz A, Lichty BD, Xing Z: Mucosal luminal manipulation of T cell geography switches on protective efficacy by otherwise ineffective parenteral genetic immunization. J Immunol 2007, 178:2387-2395

30. Small C-L, McCormick S, Gill N, Kugathasan K, Santosuosso M, Donaldson N, Heinrichs DE, Ashkar A, Xing Z: NK cells play a critical protective role in host defense against acute extracellular Staphylococcus aureus bacterial infection in the lung. J Immunol 2008, 180: $5558-5568$

31. Vermaelen K, Pauwels R: Accurate and simple discrimination of mouse pulmonary dendritic cell and macrophage populations by flow cytometry: methodology and new insights. Cytometry A 2004, 61: 170-177

32. Wolf AJ, Linas B, Trevejo-Nunez GJ, Kincaid E, Tamura T, Takatsu K, Ernst JD: Mycobacterium tuberculosis infects dendritic cells with high frequency and impairs their function in vivo. J Immunol 2007, 179: 2509-2519

33. Ngai P, McCormick S, Small C, Zhang X, Zganiacz A, Aoki N, Xing Z: Gamma interferon responses of CD4 and CD8 T-cell subsets are quantitatively different and independent of each other during pulmonary Mycobacterium bovis BCG infection. Infect Immun 2007, 75: 2244-2252

34. Egen JG, Rothfuchs AG, Feng CG, Winter N, Sher A, Germain RN: Macrophage and $T$ cell dynamics during the development and disintegration of Mycobacterial granulomas. Immunity 2008, 28:271-284

35. Axelrod S, Oschkinat H, Enders J, Schlegel B, Brinkmann V, Kaufmann SHE, Haas A, Schaible UE: Delay of phagosome maturation by a mycobacterial lipid is reversed by nitric oxide. Cell Microbiol 2008, 10:1530-1545

36. Xing Z, Zganiacz A, Santosuosso M: Role of IL-12 in macrophage activation during intracellular infection: IL-12 and mycobacteria synergistically release TNF-\{alpha\} and nitric oxide from macrophages via IFN-\{gamma\} induction. J Leukoc Biol 2000, 68:897-902

37. Nair S, Ramaswamy PA, Ghosh S, Joshi DC, Pathak N, Siddiqui I, Sharma P, Hasnain SE, Mande SC, Mukhopadhyay S: The PPE18 of Mycobacterium tuberculosis interacts with TLR2 and activates IL-10 induction in macrophage. J Immunol 2009, 183:6269-6281

38. Redford PS, Boonstra A, Read S, Pitt J, Graham C, Stavropoulos E, Bancroft GJ, O'Garra A: Enhanced protection to Mycobacterium tuberculosis infection in IL-10-deficient mice is accompanied by early and enhanced Th1 responses in the lung. Eur J Immunol 2010, 40:2200-2210
39. Yahagi A, Umemura M, Tamura T, Kariyone A, Begum MD, Kawakami K, Okamoto Y, Hamada S, Oshiro K, Kohama H, Arakawa T, Ohara N, Takatsu K, Matsuzaki G: Suppressed induction of mycobacterial antigen-specific Th1-type CD4+ T cells in the lung after pulmonary mycobacterial infection. Int Immunol 22:307-318

40. Bai H, Cheng J, Gao X, Joyee AG, Fan Y, Wang S, Jiao L, Yao Z, Yang $\mathrm{X}$ : IL-17/Th17 promotes type $1 \mathrm{~T}$ cell immunity against pulmonary intracellular bacterial infection through modulating dendritic cell function. J Immunol 2009, 183:5886-5895

41. Heo YJ, Joo YB, Oh HJ, Park MK, Heo YM, Cho ML, Kwok SK, Ju JH, Park KS, Cho SG, Park SH, Kim HY, Min JK: IL-10 suppresses Th17 cells and promotes regulatory T cells in the CD4+ T cell population of rheumatoid arthritis patients. Immunol Lett 2010, 127:150-156

42. Pecora ND, Fulton SA, Reba SM, Drage MG, Simmons DP, UrankarNagy NJ, Boom WH, Harding CV: Mycobacterium bovis BCG decreases MHC-II expression in vivo on murine lung macrophages and dendritic cells during aerosol infection. Cell Immunol 2009, 254:94104

43. Bilenki L, Gao X, Wang S, Yang J, Fan Y, Han X, Qiu H, Yang X: Dendritic cells from mycobacteria-infected mice inhibits established allergic airway inflammatory responses to ragweed via IL-10- and IL-12-secreting mechanisms. J Immunol 184:7288-7296

44. Wang J, Wakeham J, Harkness R, Xing Z: Macrophages are a significant source of type 1 cytokines during mycobacterial infection J Clin Invest 1999, 103:1023-1029

45. Lagranderie M, Nahori MA, Balazuc AM, Kiefer-Biasizzo H, Lapa e Silva JR, Milon G, Marchal G, Vargaftig BB: Dendritic cells recruited to the lung shortly after intranasal delivery of Mycobacterium bovis BCG drive the primary immune response towards a type 1 cytokine production. Immunology 2003, 108:352-364

46. Saunders BM, Cooper AM: Restraining mycobacteria: role of granulomas in mycobacterial infections. Immunol Cell Biol 2000, 78:334341

47. Denis M, Buddle BM: Bovine dendritic cells are more permissive for Mycobacterium bovis replication than macrophages, but release more IL-12 and induce better immune T-cell proliferation. Immunol Cell Biol 2008, 86:185-191

48. Wang J, Thorson L, Stokes RW, Santosuosso M, Huygen K, Zganiacz A, Hitt M, Xing Z: Single mucosal, but not parenteral, immunization with recombinant adenoviral-based vaccine provides potent protection from pulmonary tuberculosis. J Immunol 2004, 173:6357-6365

49. Ely KH, Cauley LS, Roberts AD, Brennan JW, Cookenham T, Woodland DL: Nonspecific recruitment of memory CD8+ T cells to the lung airways during respiratory virus infections. J Immunol 2003, 170: 1423-1429

50. McElvania Tekippe E, Allen IC, Hulseberg PD, Sullivan JT, McCann JR, Sandor M, Braunstein M, Ting JP: Granuloma formation and host defense in chronic Mycobacterium tuberculosis infection requires PYCARD/ASC but not NLRP3 or caspase-1, PLoS One 5:e12320

51. Fossiez F, Banchereau J, Murray R, Van Kooten C, Garrone P, Lebecque S: Interleukin-17. Int Rev Immunol 1998, 16:541-551

52. Fulton SA, Martin TD, Redline RW, Henry Boom W: Pulmonary immune responses during primary Mycobacterium bovis-CalmetteGuerin bacillus infection in C57BI/6 mice. Am J Respir Cell Mol Bio 2000, 22:333-343

53. Cooper AM, Dalton DK, Stewart TA, Griffin JP, Russell DG, Orme IM: Disseminated tuberculosis in interferon gamma gene-disrupted mice. J Exp Med 1993, 178:2243-2247

54. Cooper AM, Magram J, Ferrante J, Orme IM: Interleukin 12 (IL-12) is crucial to the development of protective immunity in mice intravenously infected with mycobacterium tuberculosis. J Exp Med 1997 186:39-45

55. Flynn JL, Goldstein MM, Chan J, Triebold KJ, Pfeffer K, Lowenstein CJ, Schreiber R, Mak TW, Bloom BR: Tumor necrosis factor-alpha is required in the protective immune response against Mycobacterium tuberculosis in mice. Immunity 1995, 2:561-572

56. Kaufmann SH, Ladel CH, Flesch IE: T cells and cytokines in intracelIular bacterial infections: experiences with Mycobacterium bovis BCG. Ciba Found Symp 1995, 195:123-132; discussion 132-126

57. Mogues T, Goodrich ME, Ryan L, LaCourse R, North RJ: The relative importance of $T$ cell subsets in immunity and immunopathology of airborne Mycobacterium tuberculosis infection in mice. J Exp Med 2001, 193:271-280 
58. Olsen AW, Brandt L, Agger EM, van Pinxteren LA, Andersen P: The influence of remaining live BCG organisms in vaccinated mice on the maintenance of immunity to tuberculosis. Scand J Immunol 2004, 60:273-277

59. Molloy A, Laochumroonvorapong P, Kaplan G: Apoptosis, but not necrosis, of infected monocytes is coupled with killing of intracellular Bacillus Calmette-Guerin. J Exp Med 1994, 180:1499-1509

60. Armbruster C, Junker W, Vetter N, Jaksch G: Disseminated Bacille Calmette-Guerin infection in an AIDS patient 30 years after BCG vaccination. J Infect Dis 1990, 162:1216

61. Rocha-Ramirez LM, Estrada-Garcia I, Lopez-Marin LM, SeguraSalinas E, Mendez-Aragon P, Van Soolingen D, Torres-Gonzalez R, Chacon-Salinas R, Estrada-Parra S, Maldonado-Bernal C, LopezMacias C, Isibasi A: Mycobacterium tuberculosis lipids regulate cytokines. TLR-2/4 and MHC class II expression in human macrophages. Tuberculosis (Edinb) 2008, 88:212-220

62. Jacobs M, Fick L, Allie N, Brown N, Ryffel B: Enhanced immune response in Mycobacterium bovis Bacille Calmette Guerin (BCG)infected IL-10-deficient mice. Clin Chem Lab Med 2002, 40:893-902
63. Tjarnlund A, Guirado E, Julian E, Cardona PJ, Fernandez C: Determinant role for Toll-like receptor signalling in acute mycobacterial infection in the respiratory tract. Microbes Infect 2006, 8:17901800

64. Drennan MB, Nicolle D, Quesniaux VJ, Jacobs M, Allie N, Mpagi J, Fremond C, Wagner $\mathrm{H}$, Kirschning C, Ryffel B: Toll-like receptor 2-deficient mice succumb to Mycobacterium tuberculosis infection. Am J Pathol 2004, 164:49-57

65. Kim R, Emi M, Tanabe K, Arihiro K: Tumor-driven evolution of immunosuppressive networks during malignant progression. Cancer Res 2006, 66:5527-5536

66. Higgins DM, Sanchez-Campillo J, Rosas-Taraco AG, Lee EJ, Orme IM, Gonzalez-Juarrero M: Lack of IL-10 alters inflammatory and immune responses during pulmonary Mycobacterium tuberculosis infection. Tuberculosis (Edinb) 2009, 89:149-157

67. Reljic R, Stylianou E, Balu S, Ma JK: Cytokine interactions that determine the outcome of Mycobacterial infection of macrophages. Cytokine 2010, 51:42-46 